\title{
In Defense of Psychosomatic Theory: A Critical Analysis of Allison and Heshka's Critical Analysis
}

\author{
Tatjana Van Strien \\ (Accepted 19 July 1994)
}

This article analyses Allison and Heshka's (International Journal of Eating Disorders, 13, 289-295, 1993.) critical analysis of studies supporting psychosomatic theory. Questionned first is, Allison and Heshka's contention that the obese overreport emotional eating as a result of effects of demand characteristics, social desirability, and interpersonal expectancies. These effects, however, indicate that a more plausible response would be an underreport of emotional eating. Also addressed is Allison and Heshka's (Eating Disorders: The Journal of Treatment and Prevention, 1, 31-38, 1993.) contention that a high correlation between a measurement instrument and a measure of social desirability invalidates that measurement instrument. Finally, in a rebuttal of Allison and Heshka's critical analysis of studies supporting psychosomatic theory, it is elaborated why emotional eating explains so little variance in weight gain and obesity. (C) 1995 by John Wiley \& Sons, Inc.

In "Emotion and Eating in Obesity? A Critical Analysis," Allison and Heshka (1993a) question the strength of the evidence supporting the claim of psychosomatic theory that the obese eat more than the nonobese in response to emotional distress. Based on their observation that "a measure of 'emotional eating' was highly correlated with social desirability measures" (Allison \& Heshka, 1993a, p 290), they contend that the robust finding in obesity literature, in which the obese report more emotional eating than the nonobese (Ganley, 1989), does not automatically mean that the obese actually engage more frequently in emotional eating. An alternative interpretation of the distress-intake relationship found in questionnaire/interview studies may, according to Allison and Heshka, be phrased in terms of social desirability, demand characteristics, and interpersonal expectancies: Obese subjects simply "may report more emotional eating . . . because they are complying with a social role," or because they "may be 'overcompliant' and dutifully agree with or report what the therapist wishes to hear" (Allison \& Heshka,

Tatjana van Strien, Ph.D. is Staff Member at the Department of Clinical Psychology at the University of Nijmegen. Address reprint requests to Dr. Van Strien, Vakgroep Klinische Psychologie en Persoonlijkheidsleer, Katholieke Universiteit Nijmegen, Postbus 9104, Nijmegen. 
1993a, p 290). They then proceed in a "critical analysis" to find fault with all studies supporting psychosomatic theory.

In this article it is first questionned whether, in view of the above mentioned effects, overreport of emotional eating is the most plausible response of the obese. Underreport of emotional eating would not only be more logical, but also more consistent with Allison and Heshka's observed correlation between a measure of emotional eating and measures of social desirability (Allison \& Heshka, 1993b). Subsequently addressed is the issue of what it means for a measurement instrument in terms of its validity if it shows high associations with measures of social desirability. Finally, it will be explained why emotional eating explains so little variance in weight gain and obesity.

\section{DEMAND CHARACTERISTICS AND SOCIAL DESIRABILITY}

The effects of demand characteristics of the research situation should be discerned from social desirability effects, as consistent tendencies of subjects to comply with the demand characteristics of the research situation will be elicited differently by the perceived social desirability of the behavior under study. According to Jackson and Messick (1961), only when this behavior has neutral social desirability for the subjects, will the subjects comply with the perceived experimental hypothesis. However, this is not the case when this behavior is highly contaminated with social desirability. Then social desirability is the dominant response determinant. In questionnaire/interview studies the effects of demand characteristics and social desirability effects may result in the respective response sets acquiescence and social desirability. The response set, acquiescence, which is "a tendency to be agreeable in a rather submissive way, that is, a desire to say what is expected" (Rorer, 1965, p 134) may result from the motivation of subjects to be supportive and compliant to the perceived experimental hypothesis (Orne, 1962). The response set social desirability, that is, a tendency to consciously dissemble a self-report by denying socially undesirable characteristics and admitting socially desirable characteristics, may result from the subject's willingness to make a good impression on the investigator (Riecken, 1962).

For reasons that will be discussed shortly, in research on differences between normal weight and obese subjects, acquiescence may be the dominant response set in the normal weight subjects. However, in the obese, the response set social desirability is more plausible. The tendency to give socially desirable responses is associated with a need to be accepted and approved of socially (McGee, 1962a, 1962b), and obese subjects have shown to be more concerned than normal weight subjects with self-presentation (for references, see Van Strien, 1985). This is probably because of their deviant status in a culture where slimness is the desired norm. Self-reports of eating behavior may especially be distorted by impression management in the obese (Stunkard \& Messick, 1985 ) in the sense that it is socially desirable for obese subjects to endorse questions about being on a diet and not to endorse those about emotional eating. Support for this latter contention is given by Allison and Heshka themselves (1993b). Inspection of the above mentioned high correlation between a measure of emotional eating and measures of social desirability (Allison \& Heshka, 1993a) revealed that this pertained to a negative correlation between a measure of emotional eating and a measure of social desirability $(r=-.35, p=.002)$, meaning that subjects who tend to respond in more socially desirable ways also report lower levels of emotional eating.

In contrast to obese subjects, it seems plausible to hypothesize that normal weight 
subjects are less motivated to give socially desirable responses to questions on dieting and emotional eating. This inclination, together with the fact that normal weight individuals are possibly in general less concerned than the obese about self-presentation, makes it highly plausible that normal weight subjects are more motivated to support the perceived experimental hypothesis than to give socially desirable responses and that acquiescence is their dominant response set.

The contention that acquiescence is the dominant response set in normal weight subjects, but social desirability in the obese, was empirically supported by Van Strien (1985). The tendency of obese subjects to give socially desirable responses, and the low social desirability of endorsement of questions on emotional eating, make overreport of emotional eating highly improbable. Underreport of emotional eating in the obese would be a far more plausible response.

\section{SOCIAL DESIRABILITY SCALES: ONLY FAKING?}

As previously stated, Allison and Heshka (1993b) found significant associations between a measure of emotional eating (i.e., the emotional eating scale of the Dutch Eating Behaviour Questionnaire [DEBQ]; Van Strien, Frijters, Bergers, \& Defares, 1986) and measures of social desirability. Furthermore, a correlation of . 94 was found between the mean desirability ratings of items of the emotional eating scale and the proportion of people endorsing these items (Allison \& Heshka, 1993b). Although the latter finding merely points to a bias in the tendency of the average person to say good rather than bad things about him or herself, the first finding more significantly indicates how much of the variance in emotional eating scores is explained by individual differences in this regard.

What do these findings mean in terms of the validity or invalidity of the DEBQ emotional eating scale? Does this mean that much of the variance in emotional eating scores is explained by individual differences with regard to the tendency to consciously dissemble a self-report by denying socially undesirable characteristics and admitting socially desirable ones? In other words, and this is the position taken by Allison and Heshka (1993b), is this emotional eating scale largely invalidated by individual differences in the tendency to fake good?

Most of the debate characterized by Wiggins (1973) as "the response style controversy" took place in the 1950s and 1960s. During these two decades, Edwards (1957, 1964) convincingly showed that individual differences in self-expressed desirability explain much of the variance in most self-inventories. Indeed, social desirability or as Nunnally (1967) prefers to describe it, the tendency to say good rather than bad things about oneself, was found to be the dominant factor in most self-inventories. However, although some believed this meant that self-inventories in general only measure individual differences with regard to the tendency to give socially desirable responses, or put differently, that all self-inventories are invalidated by individual differences with regard to the tendency to fake good, an entirely different position was taken by others (for overviews see: Nunnally, 1967; Wiggins, 1973). They defended that a high association between scores on a measure of social desirability and scores on a self-inventory does "not invalidate the latter, but rather serves to show that adjustment and self desirability (or self-esteem) are much the same thing . . . that, to picture one's self as socially desirable, one must know what is desirable in particular situations, and . . . only a poorly adjusted person would be so unfamiliar with social expectations as not to know 
how to 'fake good' on a self-inventory" (Nunnally, 1967, pp 480,481). Empirical support for the contention that social desirability scales measure more substance than style was found in a study by McCrae and Costa (1983), in which negative relationships were found between scales for social desirability and various measures of neuroticism. Further, the external validity of self-reports decreased rather than increased when they were corrected for social desirability.

It is Nunnally's contention that measures of social desirability are neither pure measures of faking nor pure measures of adjustment but rather a combination of: (1) actual adjustment of the individual, (2) knowledge the individual has about his or her own traits, and (3) frankness of the individual in stating what he or she knows (Nunnally, 1967, p 481). For the DEBQ emotional eating scale this means that one does this scale no justice if its correlation with social desirability is solely interpreted as sign of its invalidity. It also is a sign of its validity, as these correlations also point to the prevalence in emotional eating scores of substantive personality traits: self-knowledge, actual adjustment, and self-esteem. This last observation is consistent with the proposed lower adjustment and distinctive personality of high emotional eaters in psychosomatic theory (Kaplan \& Kaplan, 1957; Ganley, 1989).

\section{EMOTIONAL EATING AND OBESITY}

Allison and Heshka (1993b) also attempted to replicate the finding in psychosomatic theory that the obese report more emotional eating than the nonobese. Although they obtained a significant correlation between obesity and emotional eating scores, they conclude that "the effect is nil," as "emotional eating and obesity share less than $1 \%$ of their respective variances." They then proceed in their critical analysis publication to altogether question the validity of the contention of psychosomatic theory that the obese engage in emotional eating more frequently than do the nonobese, by critically reviewing the existing literature on this topic.

Upon close examination, Allison and Heshka's critical analysis is seriously flawed. Although they do, for example, cite Slochower's (1983) conclusion "that laboratory studies fail to consistently demonstrate that the obese increase their intake in response to emotional distress" (Allison and Heshka, 1993a, p 292), they fail to mention that Slochower subsequently managed to show that the obese do overeat in response to certain types of stressors, and that this overeating occurs, because "it works," that is, because it has an anxiety-reducing function (Slochower, 1993).

Furthermore, it is not true that Ganley's discount of the null findings from studies that did not find increased consumption for obese subjects in response to arousal is post hoc as Allison and Heshka (1993a, p 292) want us to believe. The fact of the matter is that Ganley based his discount of null findings, for the reason that increased eating in response to arousal only occurs with high palatable foods but not crackers, on the outcome of a study by McKenna (1972). In this study, in addition to arousal conditions, the quality of test food was manipulated by offering subjects either bland cookies or "extremely appetizing and tasty" chocolate chip cookies (see also: Ganley, 1989, pp 354,355).

The main reason I find Allison and Heshka's critical analysis seriously flawed, however, is that I find their hypothesized overreport of emotional eating in self-reports of the obese, as has already been elaborated upon, highly improbable. But there are other reasons. It is in my opinion more remarkable when any obese-normal differences in 
either reported or actual eating behavior are found, than not, as there are various factors that may blur obese-normal differences. One reason why obese-normal differences in self-reported or actual eating may be blurred is that effects of demand characteristics and social desirability on self-reports and actual behavior are, as has already been elaborated upon, elicited differently in the normal weight and the obese. For example, in selfreports of emotional eating, the response sets acquiescence and social desirability may result in, respectively, overreport of emotional eating in the normal weight and underreport of emotional eating in the obese, and this minimizes differences between the weight groups. As a consequence the robust finding in obesity literature that the obese report more emotional eating than the nonobese actually indicates a higher prevalence of emotional eating in the obese. This is strong evidence for the validity of psychosomatic theory.

Finally it is only logical that emotional eating explains little variance in weight gain and obesity, if one considers that these also depend on physiological variables. In addition dieting and sociocultural variables may act as confounders and have as a result that a high degree of emotional eating can be found in all weight categories, and not only the obese. In fact, it can even be questioned whether any fair proof for psychosomatic theory can be found by comparing weight groups on the basis of measured body weight alone (see further: Pudel, 1978; Van Strien, 1986, pp 19-20). So when any significant effects of emotional eating in weight gain and obesity are found, these should probably better be taken serious, instead of dismissed as being of nil importance.

\section{SOME FINAL REMARKS}

Effects of demand characteristics and social desirability constitute serious problems for the validity of outcomes of research, especially if these response tendencies are elicited differently in various subsamples. This is probably the case in subsamples of normal weight and obese subjects. The prevalence of these effects can be reliably assessed by measurement instruments for acquiescence and social desirability. However, it should be discouraged to statistically control for these effects by partialing them out of correlation/regression analyses, as Allison and Heshka (1993a) suggest, as one may then not only control for (unwanted) response style, but also for (wanted) substantive personality traits (see McCrae \& Costa, 1983).

In addition, the assessment of differences between groups of normal weight and obese subjects should be discouraged. As already mentioned, there are so many factors, capable of blurring obese-normal differences, that it makes one wonder that any obesenormal differences whatsoever are found. And if any differences in, for example, selfconcept are shown, it can never be ruled out that they are the result of the discrimination faced by the overweight, and not the cause. Instead, assessment of eating behavior regardless of body weight seems to be a more promising approach, as can be illustrated by the fruitful body of research inspired by restraint theory (Herman \& Polivy, 1980). Without the Restraint scale this theory could never have been originated. Assessment of eating behavior regardless of body weight was also the impetus for the construction of the DEBQ (Van Strien et al., 1986; Van Strien, 1986).

Finally Allison and Heshka (1993b) suggest that the prospective measurement of eating behavior by asking individuals to prospectively record moods stresses and eating behavior for a certain period of time is less susceptible to socially desirable response sets than simply asking people about their eating behavior by means of a questionnaire. 
However, this self-monitoring is a costly and time-consuming method, especially when large numbers of people are involved. Also, there is a conflict between the greater accuracy of self-monitoring and the fact that it is a reactive procedure (Wardle \& Beales, 1987). Indeed, record keeping or self-monitoring of specific behavior, thoughts, or feelings in relation to eating is a vital component of behavior modification and treatment of obesity (Wilson, 1980). "Not only is self-monitoring the mainstay of behavioural assessment of obesity; it also is part of the behavior change process . . . in that it alone can result in significant weight loss" (Wilson, 1980, pp 332-333). Thus, the disadvantages of measurement of eating behavior by means of a questionnaire should be carefully weighed against the disadvantages of self-monitoring of eating behavior.

\section{REFERENCES}

Allison, D. B., \& Heshka, S. (1993a). Emotion and eating in obesity? A critical analysis. International Journal of Eating Disorders, 13, 289-295.

Allison, D. B., \& Heshka, S. (1993b). Social desirability and response bias in self-reports of "emotional eating." Eating Disorders: The Journal of Treatment and Prevention, 1, 31-38.

Edwards, A. L. (1957). The social desirability variable in personality assessment and research. New York: Dryden.

Edwards, A. L. (1964). Social desirability and performance on the MMPI. Psychometrica, 29, 295-308.

Ganley, R. M. (1989). Emotion and eating in obesity: A review of the literature. International Journal of Eating Disorders, 8, 343-361.

Herman, C. P., \& Polivy, J. (1980). Restrained eating. In A. J. Stunkard (Ed.), Obesity (pp. 208-225). Philadelphia: WB Saunders Company.

Jackson, D. N., \& Messick, S. (1961). Acquiescence and desirability as response determinants on the MMPI. Educational and Psychological Measurement, 21, 771-790.

Kaplan, H. I., \& Kaplan, H. S. (1957). The psychosomatic concept of obesity. Journal of Nervous and Mental Disease, 125, 181-201.

McCrae, R. R., \& Costa, P. T. (1983). Social Desirability scales: More substance than style. Journal of Consulting and Cinical Psychology, 51, 882-888.

McGee, R. K. (1962a). The relationship between response style and personality variables: II. The prediction of independent conformity behaviour. Journal of Abnormal Social Psychology, 65, 347-351.

McGee, R. K. (1962b). Response style as a personality variable: By what criterion? Psychological Bulletin, 59 , 284-295.

McKenna, R. J. (1972). Some effects of anxiety level and food cues on the eating behaviour of obese and normal subjects: A comparison of the Schachterian and psychosomatic concepts. Journal of Personality and Social Psychology, 22, 311-319.

Nunnally, J. C. (1967). Psychometric theory. New York: McGraw-Hill.

Orne, M. T. (1962). On the social psychology of the psychological experiment: With particular reference to demand characteristics and their implications. American Psychologist, 17, 776-783.

Pudel, V. (1978). Zur psychogenese und therapie der adipositas. Berlin: Springer-Verlag.

Riecken, W. H. (1962). A program for research on experiments in social psychology. In N. F. Washburne (Ed.), Decision, values and groups (Vol. 11, pp. 25-41). New York: Pergamon Press.

Rorer, L. G. (1965). The great response style myth. Psychological Bulletin, 63, 129-156.

Slochower, J. A. (1983). Excessive eating: The role of emotions and environment. New York: Human Sciences Press, Inc.

Stunkard, A. J., \& Messick, S. (1985). The Three-Factor Eating Questionnaire to measure dietary restraint, disinhibition and hunger. Journal of Psychosomatic Research, 29, 71-83.

Van Strien, T. (1985). On longitudinal versus cross-sectional studies of obesity: Possible artefacts. International Journal of Obesity, 9, 323-333.

Van Strien, T. (1986). Eating behaviour, personality traits and body mass. Lisse: Swets \& Zeitlinger B.V.

Van Strien, T., Frijters, I. E. R., Bergers, G. P. A., \& Defares, P. B. (1986). The Dutch Eating Behaviour Questionnaire (DEBQ) for assessment of restrained, emotional and external eating behavior. International Journal of Eating Disorders, 5, 295-313.

Wardle, J., \& Beales, S. (1987). Restraint and food intake: An experimental study of eating patterns in the laboratory and in normal life. Behavior Research and Therapy, 25, 179-185.

Wiggins, J. S. (1973). Personality and prediction: Principles of personality assessment. Reading, MA: AddisonWesley Publishing Company.

Wilson, G. T. (1980). Behavior modification and treatment of obesity. In A. J. Stunkard (Ed.), Obesity (pp. 325-344). Philadelphia: W.B. Saunders Company. 